\title{
Percepções dos Professores Quanto à Inclusão de Alunos com Deficiência em Aulas de Educação Física
}

\author{
Márcia Greguol Gorgatti * \\ Dante de Rose Júnior **
}

\begin{abstract}
RESUMO: O objetivo deste estudo foi analisar as percepções de professores de educação física do sistema regular de ensino diante da inclusão de alunos com deficiência. Para tanto, 90 professores de educação física escolar responderam a uma escala com 18 afirmações. Pode-se observar que a percepção geral dos professores pesquisados foi negativa para com a inclusão. O pessimismo mais forte dos professores foi por não se sentirem preparados para lidar com alunos com deficiência. Os professores com menor tempo de experiência mostraram visões mais positivas no que se refere aos benefícios de todos os alunos com a inclusão.
\end{abstract}

Palavras-chave: Iniquidade social. Educação especial. Crianças portadoras de deficiências. Preconceito.

\section{INTRODUÇÃO}

Especialmente desde o final da década de 1980, muito tem-se discutido sobre o movimento de inclusão que o Governo Federal vem tentando implementar nos estabelecimentos do sistema regular de ensino (BRASIL, 1988; LDB, 1996; PNE, 2001). Os professores, que até então encaravam crianças com deficiência como uma realidade muito distante, agora são mobilizados a fazer cursos e a se atualizar para recebê-las.

Talvez por confundirem deficiência com doença, talvez por comodismo ou total falta de informação, o fato é que muitos professores ainda atualmente privam seus alunos com deficiência da oportunidade

* Professora Doutora. Centro de Educação Física e Esporte. Universidade Estadual de Londrina. Londrina, PR. Brasil. E-mail: mgreguol@gmail.com / mgreguol@uel.br

** Doutor (Livre Docente). Escola de Artes, Ciências e Humanidades. Universidade de São Paulo. São Paulo, SP, Brasil. E-mail: danrose@usp.br 
crucial de vivenciarem experiências motoras e recreativas, o que fatalmente trará consequências por vezes irreparáveis. De fato, não é suficiente apenas a criação de instrumentos legais que assegurem o ingresso de "todos" à escola. Mais do que isso, é preciso que se modifiquem atitudes, comportamentos, visões estigmatizadas.

Após a assinatura da Declaração de Salamanca, em 1994, o Brasil atravessa um momento de grandes revisões na área do atendimento às crianças com deficiência e uma das maiores discussões diz respeito à formação dos professores. No entendimento de alguns educadores, não seria necessário formar professores especializados no ensino para crianças com deficiência, já que esta tarefa passaria a ser de todos, em vista do movimento de inclusão.

Para Baumel e Castro (2003), a principal ideia da Declaração de Salamanca foi sua "orientação inclusivista", considerando que as escolas regulares, ao atingirem a educação para todos, devem ser o ponto de partida para a criação de comunidades solidárias e de uma sociedade que seja capaz de incluir. Nesse novo conceito, a escola, ao invés de encarar as diferenças como dificuldades, considera-as como oportunidades para a criação de um ambiente educativo mais rico para todos.

Pedrinelli (2002) afirma que os professores que não promovem a inclusão em suas aulas apresentam uma das duas características: ou uma atitude "segregadora", por entenderem que devido à dificuldade ou à diferença de aprendizagem os alunos com deficiência deveriam estar em contextos segregados; ou à crença de que são desprovidos de conhecimentos para atuar com a diferença, não sabendo como e o que fazer. Baumel e Castro (2003) destacam que é preciso estabelecer para os professores um processo de desenvolvimento profissional, inovando a prática pedagógica com novas possibilidades de recursos e materiais para o ensino de todos os alunos. Além disso, ressaltam a importância da contínua busca pelo aperfeiçoamento pessoal e profissional do professor.

Segundo Mantoan (2003), a proposta de inclusão exige que a escola se identifique com determinados princípios educacionais e que os professores tenham atitudes compatíveis com esses princípios. A

Movimento, Porto Alegre, v. 15, n. 02, p. 119-140, abril/junho de 2009. 
capacitação de professores é o primeiro passo para a inclusão escolar ter sucesso. De modo geral, é um fator que assegurará o progresso, a qualidade e a manutenção de todos os alunos na escola, já que, preparado, o professor terá competência para avaliar qual tipo de intervenção vai favorecer o desenvolvimento dos alunos, o impacto da inclusão para os alunos sem deficiência, se há modificação no desempenho da aprendizagem das crianças e como esse desempenho pode ser potencializado (FARIAS, 2003).

Rodrigues (2003) afirma que a educação física tem-se mantido à margem do movimento de inclusão, dominante no discurso nacional desde a década de 90. Embora muitas crianças com deficiência até consigam ter acesso à escola regular, em muitos casos, são dispensadas das aulas de educação física, normalmente pela insegurança por parte do professor. Segundo o autor, a educação física é um direito, não uma opção descartável. Sendo assim, nenhum aluno pode ser dispensado da disciplina, ainda que de seu aspecto teórico.

Tendo em vista a relevância e a atualidade do tema, o objetivo deste estudo foi analisar as percepções dos professores de educação física do sistema regular de ensino diante da inclusão de alunos com deficiência nas suas aulas. Este estudo teve ainda como objetivo relacionar as percepções demonstradas ao tempo de experiência e ao sexo do professor.

\section{MÉTOdo}

O presente estudo trata-se de uma pesquisa descritiva, na qual são levantadas, de forma transversal, características dos sujeitos envolvidos sem a interferência do pesquisador.

\subsection{AMOSTRA E PROCEDIMENTOS}

Para a realização deste estudo, contou-se com a participação de 90 professores de educação física do sistema regular de ensino da cidade São Paulo, tanto de escolas particulares como de escolas públicas estaduais. Todos os professores eram formados em educação física e foram classificados por sexo (59 do sexo feminino e 31 do

Movimento, Porto Alegre, v. 15, n. 02, p. 119-140, abril/junho de 2009. 
sexo masculino), tempo de experiência no magistério (13 com menos de dois anos de experiência; 32 com experiência entre dois e dez anos; e 45 com experiência superior a dez anos) e tipo de escola (61 de escolas públicas e 29 de escolas particulares). As escolas procuradas nessa fase foram escolhidas de forma aleatória nas regiões Sul e Oeste da cidade de São Paulo. Foram avaliados professores que trabalhavam em apenas uma escola, a fim de que os dados obtidos pudessem ser mais específicos.

Foi aplicada uma escala para os professores do ensino regular público e particular. A intenção foi avaliar quais percepções os professores de educação física apresentavam diante de alunos com deficiência inclusos nas classes regulares e qual o tipo de apoio que eles recebiam para a otimização de seu trabalho junto a essa população especial. A escala foi adaptada dos modelos já validados de Sideridis e Chandler (1997) e Kozub e Porretta (1998) e encontra-se no ANEXO 1. Para a construção da escala utilizada neste estudo, foram elaboradas trinta afirmações, que posteriormente foram mostradas para cinco profissionais especialistas na área de educação especial e educação física adaptada. Após serem verificadas as sugestões, o número de afirmações foi reduzido para 18.

$\mathrm{Na}$ escala aplicada foram então apresentadas as 18 afirmações, para as quais foram utilizados cinco níveis de respostas: não se aplica, discordo totalmente, discordo quase totalmente, concordo quase totalmente e concordo totalmente. A alternativa "não se aplica" deveria ser respondida pelo professor quando este não tivesse opinião formada sobre alguma das afirmações. As afirmações abordaram as opiniões dos professores sobre a presença de alunos com deficiência nas aulas de educação física, bem como o apoio recebido pela direção da escola. Também foi enfocada a preparação que o professor julgava necessária para lidar com esses alunos e quais os critérios utilizados para a avaliação dos casos "especiais". As afirmações de um a dez diziam respeito à forma como o professor se posicionava diante da inclusão de alunos com deficiência em suas aulas; as de números 11 a 14 diziam respeito à forma como o professor percebia os benefícios da inclusão para todos os alunos; por fim, as de números 15 a 18

Movimento, Porto Alegre, v. 15, n. 02, p. 119-140, abril/junho de 2009. 
abordavam a opinião dos professores com relação à estrutura e ao estímulo oferecidos pelas escolas.

Os professores responderam à escala de forma individual, sem a interferência dos pesquisadores. Também não foi necessário que se identificassem, nem tampouco à sua escola. As respostas obtidas nas escalas foram tabuladas e relacionadas ao sexo e ao tempo de experiência dos professores. As respostas das afirmações de números 15 a 18 foram comparadas também quanto ao tipo de escola (pública ou particular) na qual o professor trabalhava. Os resultados foram dispostos em tabelas de frequência simples e tabelas de frequência cruzadas. A fim de se verificar se existiam diferenças entre as proporções obtidas para cada afirmação, foi utilizado o teste Qui-Quadrado e o nível de significância adotado foi de 0,05 .

Este trabalho foi desenvolvido com a aprovação do Comitê de Ética em Pesquisa da Escola de Educação Física e Esporte da Universidade de São Paulo.

\section{Resultados E discussão}

Os professores foram categorizados quanto ao sexo, ao tipo de escola (pública ou particular) e ao tempo de experiência na docência. Não existiu associação na distribuição dos professores quanto ao sexo e ao tipo de escola, entre tempo de experiência e tipo de escola nem entre tempo de experiência e sexo $(p=0,973 ; 0,424$; e 0,386 , respectivamente).

Quanto à escala aplicada aos professores (Anexo 1), as afirmações, com exceção das de números 10 e 14, colocavam situações que expressavam uma atitude positiva e otimista com relação à presença de alunos com deficiência nas aulas. Ao ler cada afirmação, o professor expressava-se utilizando uma das seguintes respostas: 0 , para não se aplica; 1, para discordo totalmente da afirmação; 2, para discordo quase totalmente da afirmação; 3 , para concordo quase totalmente com a afirmação; e 4, para concordo totalmente com a afirmação. Dessa forma, quanto menor o valor assinalado pelo professor, menor o seu otimismo com relação à afirmação proposta. Para as

Movimento, Porto Alegre, v. 15, n. 02, p. 119-140, abril/junho de 2009. 


\section{Astigor Originais}

Márcia Gorgatti e Dante Rose Jr.

questões de números 10 e 14, que colocavam afirmações negativas, a situação foi inversa, ou seja, quanto menor o peso assinalado pelo professor, maior o seu otimismo. A TABELA 1 mostra um resumo geral da distribuição das respostas dos professores nas 18 questões.

Tabela 1. Resumo geral das respostas da escala aplicada aos professores.

* Diferença significante $(\mathrm{p}<0,05)$

\begin{tabular}{|c|c|c|c|c|c|c|c|c|c|}
\hline & & & & & & \multicolumn{3}{|c|}{ Respostas } & \multirow{2}{*}{$\frac{\text { Teste } \chi^{2}}{\mathrm{P}}$} \\
\hline & & 0 & 1 & 2 & 3 & 4 & Total & Resultado & \\
\hline \multirow{2}{*}{ Questão 1} & $\mathrm{~N}$ & 0 & 28 & 32 & 27 & 3 & 90 & \multirow{2}{*}{23,2} & \multirow{2}{*}{$0,000 *$} \\
\hline & $\%$ & $0 \%$ & $31,10 \%$ & $35,60 \%$ & $30,00 \%$ & $3,30 \%$ & $100,00 \%$ & & \\
\hline \multirow{2}{*}{ Questão 2} & $\mathrm{~N}$ & 0 & 39 & 21 & 26 & 4 & 90 & \multirow{2}{*}{28} & \multirow{2}{*}{$0,000^{*}$} \\
\hline & $\%$ & $0 \%$ & $43,30 \%$ & $23,30 \%$ & $28,90 \%$ & $4,40 \%$ & $100,00 \%$ & & \\
\hline \multirow{2}{*}{ Questão 3} & $\mathrm{~N}$ & 0 & 13 & 35 & 37 & 5 & 90 & \multirow{2}{*}{33,9} & \multirow{2}{*}{$0,000 *$} \\
\hline & $\%$ & $0 \%$ & $14,40 \%$ & $38,90 \%$ & $41,10 \%$ & $5,60 \%$ & $100,00 \%$ & & \\
\hline \multirow{2}{*}{ Questão 4} & $\mathrm{~N}$ & 0 & 20 & 34 & 31 & 5 & 90 & \multirow{2}{*}{23} & \multirow{2}{*}{$0,000^{*}$} \\
\hline & $\%$ & $0 \%$ & $22,20 \%$ & $37,80 \%$ & $34,40 \%$ & $5,60 \%$ & $100,00 \%$ & & \\
\hline \multirow{2}{*}{ Questão 5} & $\mathrm{~N}$ & 0 & 19 & 24 & 26 & 21 & 90 & \multirow{2}{*}{1,3} & \multirow{2}{*}{0,732} \\
\hline & $\%$ & $0 \%$ & $21,10 \%$ & $26,70 \%$ & $28,90 \%$ & $23,30 \%$ & $100,00 \%$ & & \\
\hline \multirow{2}{*}{ Questão 6} & $\mathrm{~N}$ & 0 & 7 & 5 & 19 & 59 & 90 & \multirow{2}{*}{84} & \multirow{2}{*}{$0,000 *$} \\
\hline & $\%$ & $0 \%$ & $7,80 \%$ & $5,60 \%$ & $21,10 \%$ & $65,60 \%$ & $100,00 \%$ & & \\
\hline \multirow{2}{*}{ Questão 7} & $\mathrm{~N}$ & 0 & 40 & 17 & 24 & 9 & 90 & \multirow{2}{*}{23,2} & \multirow{2}{*}{$0,000^{*}$} \\
\hline & $\%$ & $0 \%$ & $44,40 \%$ & $18,90 \%$ & $26,70 \%$ & $10,00 \%$ & $100,00 \%$ & & \\
\hline \multirow{2}{*}{ Questão 8} & $\mathrm{~N}$ & 0 & 16 & 27 & 31 & 16 & 90 & \multirow{2}{*}{7,9} & $0.049 *$ \\
\hline & $\%$ & $0 \%$ & $17,80 \%$ & $30,00 \%$ & $34,40 \%$ & $17,80 \%$ & $100,00 \%$ & & $0,049^{\prime \prime}$ \\
\hline Ouestão 9 & $\mathrm{~N}$ & 0 & 18 & 19 & 28 & 25 & 90 & 3.1 & $0.38-3$ \\
\hline Questao 9 & $\%$ & $0 \%$ & $20,00 \%$ & $21,10 \%$ & $31,10 \%$ & $27,80 \%$ & $100,00 \%$ & 3,1 & 0,38 \\
\hline Ouestão 10 & $\mathrm{~N}$ & 16 & 17 & 32 & 18 & 7 & 90 & 4 & 0 \\
\hline Questao 10 & $\%$ & $17,80 \%$ & $18,90 \%$ & $35,50 \%$ & $20 \%$ & $7,80 \%$ & $100,00 \%$ & 14, & $0,002^{\star}$ \\
\hline Ouestão 11 & $\mathrm{~N}$ & 0 & 5 & 21 & 35 & 29 & 90 & 22 & 000 \\
\hline Questao 11 & $\%$ & $0 \%$ & $5,60 \%$ & $23,30 \%$ & $38,90 \%$ & $32,20 \%$ & $100,00 \%$ & 22,5 & 0,000 \\
\hline & $\mathrm{N}$ & 0 & 3 & 12 & 37 & 38 & 90 & 418 & $0000 *$ \\
\hline Questão 12 & $\%$ & $0 \%$ & $3,30 \%$ & $13,30 \%$ & $41,10 \%$ & $42,20 \%$ & $100,00 \%$ & 41,8 & $0,000^{*}$ \\
\hline Oupctão 13 & $\mathrm{~N}$ & 14 & 7 & 18 & 27 & 24 & 90 & 157 & $0001 *$ \\
\hline Questao 13 & $\%$ & $15,50 \%$ & $7,80 \%$ & $20 \%$ & $30 \%$ & $26,70 \%$ & & 15,7 & $0,001^{*}$ \\
\hline Ouestão 14 & $\mathrm{~N}$ & 18 & 31 & 26 & 12 & 3 & 90 & 259 & $0000 *$ \\
\hline & $\%$ & $20 \%$ & $34,40 \%$ & $28,90 \%$ & $13,40 \%$ & $3,30 \%$ & $100,00 \%$ & 25,9 & \\
\hline Ouestão 15 & $\mathrm{~N}$ & 0 & 59 & 9 & 17 & 5 & 90 & 823 & $0000 *$ \\
\hline Questao is & $\%$ & $0 \%$ & $65,60 \%$ & $10,00 \%$ & $18,90 \%$ & $5,60 \%$ & $100,00 \%$ & 82,3 & \\
\hline Ouestãก 16 & $\mathrm{~N}$ & 0 & 74 & 8 & 6 & 2 & 90 & 158 & $0000 *$ \\
\hline Questao 10 & $\%$ & $0 \%$ & $82,20 \%$ & $8,90 \%$ & $6,70 \%$ & $2,20 \%$ & $100,00 \%$ & 158 & $0,000^{*}$ \\
\hline ดนеง 17 & $\mathrm{~N}$ & 0 & 63 & 12 & 10 & 5 & 90 & 08 & \\
\hline Questao 17 & $\%$ & $0 \%$ & $70,00 \%$ & $13,30 \%$ & $11,10 \%$ & $5,60 \%$ & $100,00 \%$ & 4 & 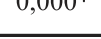 \\
\hline & $\mathrm{N}$ & 0 & 66 & 14 & 7 & 3 & 90 & & \\
\hline Q & $\%$ & $0 \%$ & $73,30 \%$ & $15,60 \%$ & $7,80 \%$ & $3,30 \%$ & $100,00 \%$ & & * \\
\hline
\end{tabular}

Movimento, Porto Alegre, v. 15, n. 02, p. 119-140, abril/junho de 2009 
A fim de se verificar se houve diferenças significativas ( $\mathrm{p}<$ $0,05)$ entre as proporções, utilizou-se o teste Qui-Quadrado. Observou-se que a diferença foi significativa em praticamente todas as questões, exceto nas de números 5 e 9 (gostar de ter alunos com deficiência e motivar todos os alunos, respectivamente), nas quais existiu uma distribuição homogênea das respostas. Na questão de número 8 (cumprir o programa de ensino proposto), o teste ficou próximo ao limite ( $\mathrm{p}$-valor $=0,048$ ), indicando certa tendência à homogeneidade entre as respostas. As questões nas quais os professores demonstraram maior otimismo quanto à presença de alunos com deficiência nas aulas regulares de educação física foram as de números 6 e 12, que afirmavam respectivamente que o professor pretendia participar de cursos para aumentar seus conhecimentos sobre os métodos de ensino para alunos com deficiência e que o professor sentia que os alunos sem deficiência se beneficiariam com a inclusão de colegas com deficiência nas aulas.

Assim, percebe-se que, embora quase a metade dos professores pesquisados $(47,8 \%)$ demonstrasse não gostar da ideia de ter alunos com deficiência nas suas aulas (afirmação número 5), 86,7\% demonstraram a intenção de fazer cursos para adquirir mais conhecimentos sobre como proceder com tais alunos e $83,3 \%$ concordaram que os alunos sem deficiência teriam benefícios com o movimento de inclusão.

$\mathrm{O}$ fato de a maioria dos professores demonstrar a intenção de fazer cursos na área de educação física adaptada pode ser reflexo da obrigatoriedade das escolas praticarem a inclusão de alunos com deficiência. Por outro lado, ao fazer cursos e conhecer mais sobre o potencial desses alunos, muitos professores podem tornar suas atitudes mais positivas e receptivas. Rizzo (1985), pesquisando 194 professores de educação física, verificou que aqueles que participavam de cursos na área de educação física adaptada se mostravam mais otimistas com relação à inclusão de alunos com deficiência nas aulas regulares.

Ao analisar diversos artigos publicados nas duas últimas décadas abordando as atitudes de professores de educação física sobre a inclusão de alunos com deficiência, Hutzler (2003) observou alguns pontos

Movimento, Porto Alegre, v. 15, n. 02, p. 119-140, abril/junho de 2009. 
que influenciavam tais comportamentos. Destacou que os profissionais do sexo feminino, aqueles que participaram de cursos na área da atividade física adaptada e aqueles com experiência prévia no trabalho com jovens com deficiência demonstravam, em geral, uma atitude mais positiva ao receber alunos com deficiência em suas turmas regulares.

As afirmações nas quais os professores mostraram um maior pessimismo foram as de número 2,7 e 15 a 18 . As afirmações 2 e 7 tratavam respectivamente do quanto o professor acreditava que os seus conhecimentos o tornavam preparado para trabalhar com alunos com deficiência e do quanto ele acreditava que utilizaria os mesmos critérios para avaliar alunos com e sem deficiência. Dos professores pesquisados, $66,6 \%$ demonstraram um pessimismo relacionado ao seu preparo para trabalhar com alunos com deficiência e 63,9\% afirmaram que não utilizam ou não utilizariam, para avaliar os alunos com deficiência, os mesmos critérios usados para os demais alunos. Outras pesquisas na bibliografia também relatam a percepção do professor de educação física com relação à sua falta de preparo para lidar com alunos com deficiência. Provavelmente, essa falta de preparo faz com que o professor não se sinta à vontade ou não demonstre otimismo em desenvolver seu trabalho junto a esta população. Quanto aos critérios de avaliação, justamente pela falta de conhecimento, os professores acreditam que não podem ser tão exigentes com seus alunos com deficiência. As pesquisas também mostram que os professores tendem a ser menos criteriosos para atribuir notas para esses alunos (KOZUB; PORRETA, 1998; LAMASTER; GAL; KINCHIN; SIEDENTOP, 1998).

Ainda tratando da atribuição de notas e do preparo do professor de educação física com relação a alunos com deficiência, Gorgatti, Penteado, Pinge e De Rose Júnior (2004) aplicaram uma escala para 10 professores de educação física que trabalhavam com crianças com deficiência.Verificaram, no estudo, que todos os professores pesquisados afirmavam usar critérios de avaliação diferenciados para os alunos com deficiência. Outros aspectos foram também salientados na pesquisa: $50 \%$ dos professores salientaram que não gostavam de trabalhar

Movimento, Porto Alegre, v. 15, n. 02, p. 119-140, abril/junho de 2009. 
com alunos com deficiência e que não possuíam conhecimento para tal; entretanto, $80 \%$ dos professores afirmaram acreditar que o movimento de inclusão nas aulas de educação física era benéfico para todos os alunos e que aqueles com deficiência eram bem aceitos por seus colegas; por fim, $90 \%$ dos professores destacaram que suas escolas não eram preparadas para receber alunos com deficiência, quer seja pela falta de adaptação estrutural, quer pela falta de apoio material ou de uma equipe multidisciplinar.

Aguiar e Duarte (2005), ao entrevistarem 67 professores de educação física de escolas públicas do Estado de São Paulo, na sua maioria com mais de 10 anos de experiência, verificaram que a maioria $(62,7 \%)$ dos professores pesquisados não se sentia preparada para lidar com alunos com deficiência. Além disso, a maioria dos professores pesquisados afirmou tentar obter novas informações sobre as necessidades de tais alunos por meio de palestras ou de leituras independentes. Embora 97\% dos professores demonstrasse perceber os possíveis benefícios advindos da prática da inclusão escolar, também afirmava que ainda eram necessárias algumas condições para que o processo pudesse ser bem sucedido. Algumas necessidades levantadas foram no que se refere à capacitação contínua dos professores, adequação de espaços e recursos materiais e apoio de equipe multidisciplinar.

\subsection{PERCEPÇÕES DOS PROFESSORES QUANTO AO PREPARO DAS ESCOLAS} (AFIRMAÇÕES 15 A 18)

Nestas afirmações, o professor deveria se posicionar sobre o quanto sua escola estava preparada adequadamente para receber alunos com deficiência, tanto com relação aos espaços, quanto aos materiais, serviços de suporte e demais recursos necessários. Nas quatro afirmações, houve uma tendência geral para o pessimismo dos professores, mostrando que esses julgam que, no geral, suas escolas estão mal preparadas e que faltam recursos materiais e espaços adequados para um trabalho apropriado com todos os alunos. Como essas afirmações disseram respeito especificamente à estrutura e ao ajustamento da escola para o sucesso da inclusão, as respostas foram comparadas

Movimento, Porto Alegre, v. 15, n. 02, p. 119-140, abril/junho de 2009. 
para professores das redes particular e pública de ensino, utilizando-se novamente o teste Qui-Quadrado.

Os resultados mostraram que, para as afirmações 15 e 18, não houve diferenças significativas entre as respostas dos professores da rede pública e da rede particular de ensino $(p=0,184$ e 0,372 , respectivamente). Essas afirmações diziam respeito à percepção do professor sobre a existência de materiais suficientes na sua escola para as aulas e sobre as adaptações estruturais na escola para a acessibilidade de todos os alunos. Em outras palavras, tanto professores da rede pública como aqueles da rede particular julgaram de forma semelhante as suas escolas quanto aos materiais para aula e à acessibilidade. No quesito materiais, embora observe-se que os professores da rede particular tenham mostrado uma tendência mais otimista do que os da rede pública, essa diferença não foi significativa.

Já para as afirmações 16 e 17, que diziam respeito, respectivamente, aos serviços de suporte (médico, fonoaudiológico, psicológico, entre outros) e aos recursos suficientes para adquirir os materiais necessários, as diferenças foram significativas $(\mathrm{p}=0,008$ para a afirmação 16 e 0,001 para a afirmação 17). Dessa forma, observou-se que os professores da rede particular avaliaram que suas escolas possuíam mais recursos para a aquisição de materiais e uma maior equipe de profissionais para prestar o apoio adequado aos alunos com deficiência. Os professores da rede pública, por outro lado, mostraram-se mais pessimistas com relação às suas escolas nesses dois fatores.

Outras pesquisas realizadas recentemente também vêm demonstrando que, além do preparo profissional adequado, os professores sentem-se, em muitas situações, inseguros com relação à inclusão de alunos com deficiência em suas aulas pela falta de espaços acessíveis e recursos materiais. Além disso, os professores manifestam, de um modo geral, a necessidade da presença de uma equipe multidisciplinar de apoio, constituída por psicólogos, fonoaudiólogos, entre outros. Há ainda a questão da possibilidade da presença de um professor auxiliar durante as aulas, bem como um número reduzido de alunos por turma (AMMAH; HODGE, 2006; GOLDER, NORWICH; BAYLISS, 2005; SKARBREVIK, 2005).

Movimento, Porto Alegre, v. 15, n. 02, p. 119-140, abril/junho de 2009. 
No presente estudo, observou-se que não existiram, no geral, associações entre os fatores e as respostas. Entretanto, há duas exceções: a associação entre tipo de escola e as respostas 16 e 17, a qual já foi exposta anteriormente, e a associação entre tempo de experiência e as respostas 13 e 14 ( $p=0,028$ e 0,018 , respectivamente), ressaltando, neste último caso, que os professores menos experientes mostram-se mais otimistas com relação à presença de alunos com deficiência em suas aulas. As afirmações 13 e 14 diziam respeito à percepção do professor sobre a forma como os alunos com deficiência eram aceitos socialmente por seus colegas na escola. Este dado vai ao encontro de outros estudos na bibliografia, que relatam que professores mais jovens e menos experientes tendem a ser mais receptivos com relação à ideia de incluir crianças com deficiência em suas aulas de educação física (RIZZO, 1985).

Em um levantamento sobre a preparação profissional de professores de educação física nos anos de 1980 e 1988, Melograno e Loovis (1991) observaram certo despreparo no que se refere aos alunos com deficiência. Mais da metade dos professores pesquisados (51\%), nas duas ocasiões, salientou que não recebiam qualquer apoio ou encorajamento por parte da direção da escola para que pudessem trabalhar com alunos nessas condições. Nas duas situações, também a maioria dos professores de educação física (75\%) acreditava que os alunos com deficiência eram excluídos do processo regular de ensino devido à "natureza de sua deficiência" e às suas "capacidades funcionais".

Ao verificarem a viabilidade do movimento de inclusão em educação física, LaMaster, Gall, Kinchin e Siedentop (1998) entrevistaram seis professores da rede regular de ensino que possuíam em suas salas alunos com algum tipo de deficiência. Os resultados indicaram que os estilos de ensino e as formas de promover a inclusão dos alunos variavam bastante, porém todos profissionais afirmaram que sentiam algum grau de frustração e culpa por não poder ou conseguir realizar um trabalho melhor com as crianças com deficiência. Tais sentimentos negativos eram atribuídos ao pouco apoio recebido da direção da escola e à falta de conhecimentos específicos sobre as deficiências. Os professores afirmaram que possuíam uma preparação

Movimento, Porto Alegre, v. 15, n. 02, p. 119-140, abril/junho de 2009. 
profissional precária a este respeito e que não eram estimulados a fazerem cursos de especialização. Segundo os autores, certamente os sentimentos de culpa e de frustração somente vieram à tona por se tratarem de profissionais competentes e apaixonados pela profissão, já que muitos poderiam simplesmente dispensar os alunos com deficiência da prática da educação física.

Buscando também investigar as atitudes de professores de educação física com relação à inclusão de alunos com deficiência nas aulas regulares, Palla e Castro (2004) aplicaram uma escala a 46 professores e a 91 estudantes de educação física. Verificaram que um grande entrave para a inclusão é a falta de experiência prática dos professores e dos estudantes no que se refere aos alunos com deficiência. De um modo geral, pôde ser observado nesse estudo que, ainda que os professores demonstrassem atitudes positivas com relação à inclusão, acreditavam ser necessária a formação continuada, maior número de horas de ensino e estágio na graduação sobre a temática da educação física adaptada e parcerias entre setores públicos e privados para a geração de verbas.

\subsection{PERCEPÇÕES DOS PROFESSORES DE ACORDO COM} OSEXOEOTEMPODEEXPERIÊNCIA

No presente estudo, embora seja possível verificar que existem diferenças na distribuição das respostas, é difícil indicar o sentido e mensurar o tamanho dessas diferenças. Para tanto, optou-se pelo aproveitamento da estrutura ordinal das respostas e pela utilização de uma estratégia para analisar as escalas, atribuindo-se pontos para cada resposta e analisando-se a média desses pontos. As respostas foram codificadas da seguinte forma:

- 1 - discordo totalmente da afirmação

- 2 pontos

• 2 - discordo quase totalmente da afirmação

-1 ponto

- Não se aplica

0 pontos

- 3 - concordo quase totalmente com a afirmação +1 ponto

• 4 - concordo totalmente com a afirmação $\quad+2$ pontos

Movimento, Porto Alegre, v. 15, n. 02, p. 119-140, abril/junho de 2009. 
Para facilitar o entendimento dos resultados, convencionou-se que valores positivos sugerem preparo, interesse e otimismo sobre a inclusão de crianças com deficiência nas aulas de educação física regulares. Para isso, as respostas das afirmações 10 e 14 foram invertidas. As TABELAS 2 e 3 mostram, respectivamente, os resultados médios das respostas para as afirmações, de acordo com o sexo dos professores e o tempo de experiência.

Tabela 2. Respostas codificadas por sexo

\begin{tabular}{|c|c|c|c|}
\hline & \multicolumn{3}{|c|}{ SEXO } \\
\hline Média & Feminino & Masculino & Total \\
\hline Questão 1 & $-0,78$ & $-0,29$ & $-0,61$ \\
\hline Questão 2 & $-0,97$ & $-0,26$ & $-0,72$ \\
\hline Questão 3 & $-0,19$ & $-0,10$ & $-0,16$ \\
\hline Questão 4 & $-0,44$ & $-0,23$ & $-0,37$ \\
\hline Questão 5 & 0,07 & 0,06 & 0,07 \\
\hline Questão 6 & 1,37 & 1,19 & 1,31 \\
\hline Questão 7 & $-0,66$ & $-0,52$ & $-0,61$ \\
\hline Questão 8 & $-0,14$ & 0,39 & 0,04 \\
\hline Questão 9 & 0,00 & 0,74 & 0,26 \\
\hline Questão 10 & 0,24 & 0,13 & 0,20 \\
\hline Questão 11 & 0,58 & 0,90 & 0,69 \\
\hline Questão 12 & 1,03 & 1,10 & 1,06 \\
\hline Questão 13 & 0,24 & 0,29 & 0,26 \\
\hline Questão 14 & 0,69 & 0,68 & 0,69 \\
\hline Questão 15 & $-1,25$ & $-0,84$ & $-1,11$ \\
\hline Questão 16 & $-1,71$ & $-1,45$ & $-1,62$ \\
\hline Questão 17 & $-1,37$ & $-1,19$ & $-1,31$ \\
\hline Questão 18 & $-1,51$ & $-1,42$ & $-1,48$ \\
\hline Total & $-0,27$ & $-0,04$ & $-0,19$ \\
\hline
\end{tabular}

Observa-se que, no geral, a tendência é levemente negativa, demonstrando certo pessimismo e descrença por parte dos professores. Esse pessimismo independe do sexo do professor, porém mostra uma pequena variação quando se analisa seu tempo de experiência. De uma maneira ampla, professores com menos tempo de experiência na escola mostram certa tendência positiva, quando comparados

Movimento, Porto Alegre, v. 15, n. 02, p. 119-140, abril/junho de 2009. 
aos demais professores, mais experientes. Independentemente da associação ao sexo ou ao tempo de experiência do professor, as afirmações 15 a 18 foram aquelas nas quais os professores mostraram-se mais pessimistas. Já nas afirmações 6 e 12 os professores mostraram uma forte tendência para o otimismo.

Tabela 3. Respostas codificadas por tempo de experiência.

\begin{tabular}{|c|c|c|c|c|}
\hline & \multicolumn{3}{|c|}{ Tempo de Experiência } & \multirow[b]{2}{*}{ Total } \\
\hline Dados & menos de 2 anos & de 2 a 10 anos & mais de 10 anos & \\
\hline Questão 1 & $-0,08$ & $-0,88$ & $-0,58$ & $-0,61$ \\
\hline Questão 2 & $-0,15$ & $-0,97$ & $-0,71$ & $-0,72$ \\
\hline Questão 3 & $-0,31$ & $-0,19$ & $-0,09$ & $-0,16$ \\
\hline Questão 4 & $-0,38$ & $-0,47$ & $-0,29$ & $-0,37$ \\
\hline Questão 5 & 1,08 & $-0,13$ & $-0,09$ & 0,07 \\
\hline Questão 6 & 1,85 & 1,16 & 1,27 & 1,31 \\
\hline Questão 7 & $-0,77$ & $-0,66$ & $-0,53$ & $-0,61$ \\
\hline Questão 8 & 0,00 & $-0,03$ & 0,11 & 0,04 \\
\hline Questão 9 & 0,69 & 0,31 & 0,09 & 0,26 \\
\hline Questão 10 & 0,31 & 0,25 & 0,13 & 0,20 \\
\hline Questão 11 & 0,85 & 0,56 & 0,73 & 0,69 \\
\hline Questão 12 & 1,08 & 0,84 & 1,20 & 1,06 \\
\hline Questão 13 & 0,46 & 0,03 & 0,36 & 0,26 \\
\hline Questão 14 & 0,85 & 0,59 & 0,71 & 0,69 \\
\hline Questão 15 & $-0,92$ & $-1,47$ & $-0,91$ & $-1,11$ \\
\hline Questão 16 & $-1,62$ & $-1,66$ & $-1,60$ & $-1,62$ \\
\hline Questão 17 & $-0,77$ & $-1,53$ & $-1,31$ & $-1,31$ \\
\hline Questão 18 & $-1,38$ & $-1,63$ & $-1,40$ & $-1,48$ \\
\hline Média Total & 0,04 & $-0,32$ & $-0,16$ & $-0,19$ \\
\hline
\end{tabular}

Pelo exposto, verifica-se que os dados mais relevantes levantados com a escala foram relacionados a três aspectos: 1) à percepção dos professores quanto à falta de preparo das escolas; 2) ao seu desejo de participar de cursos para aprender como lidar melhor com alunos com deficiência; e 3) aos benefícios que a inclusão traz para os alunos sem deficiência.

Movimento, Porto Alegre, v. 15, n. 02, p. 119-140, abril/junho de 2009. 
Mais uma vez, ressalta-se que a efetiva implementação do conceito do acesso de todos à escola parece estar seriamente ameaçada pela falta de preparo, tanto das escolas como dos professores. Como visto anteriormente, os cursos superiores de educação física, muitas vezes falham em preparar os futuros profissionais para a possibilidade da inclusão (CRUZ; FERREIRA, 2005). Nos currículos dos cursos de educação física dos professores mais antigos, provavelmente, nem sequer existia uma disciplina para este fim, já que esta é uma área mais recente (PEDRINELLI; VERENGUER, 2005). Assim, especialmente para os professores com mais tempo de formação, a ideia de incluir alunos com deficiência em suas aulas parece uma proposta fadada ao fracasso e à desorganização. Modificar este conceito vai além de cursos ou palestras eventuais. A mudança de atitudes certamente passa pelo preparo contínuo, pelo suporte de serviços de apoios e por parcerias com professores de escolas especiais, que já estes possuem experiência maior em trabalhar separadamente com crianças com deficiência.

Não se pode também esquecer das escolas. A visão negativa que a maioria dos professores demonstra sobre suas escolas mostra que estas precisam modificar suas estruturas de maneira profunda, a fim de se tornarem acessíveis para todos os alunos. E essa modificação vai muito além da questão arquitetônica. Passa certamente pela necessidade de serviços multiprofissionais de apoio, pela aquisição de materiais didáticos adequados e pelo incentivo à capacitação contínua dos profissionais que nela atuam.

\section{CONSIDERAÇõES FINAIS}

Com relação à atitude dos professores de educação física das escolas regulares diante da inclusão de alunos com deficiência em suas aulas, conclui-se que a tendência geral dos professores pesquisados foi negativa para com a inclusão. Esse pessimismo independeu do sexo dos professores ou do tempo de experiência. O pessimismo mais forte dos professores foi com relação ao fato de não se sentirem preparados para lidar com alunos que apresentem deficiências. Os professores com menor tempo de experiência mostraram-se mais

Movimento, Porto Alegre, v. 15, n. 02, p. 119-140, abril/junho de 2009. 


\section{Antifor Orifinair}

Márcia Gorgatti e Dante Rose Jr.

otimistas no que se refere aos benefícios de todos os alunos com o movimento de inclusão. Quanto à avaliação das escolas, os professores das escolas públicas mostraram acreditar que terão maiores problemas, especialmente pela falta de recursos materiais apropriados e pela falta de apoio multidisciplinar.

Dessa forma, percebe-se que ainda existem muitas barreiras a serem superadas no que se refere à inclusão de alunos com deficiência nas escolas do Brasil. Fica clara também a ideia de que a simples promulgação de leis não garante o acesso de todos à escola. É fundamental neste processo que os professores sejam devidamente preparados e esclarecidos sobre as possibilidades dos alunos com deficiência e que recebam todo o apoio da escola e do governo neste sentido. Caso contrário, a inclusão continuará sendo apenas uma ideia muito viável no papel, porém sem real aplicação prática.

\begin{tabular}{l}
\hline Teachers' Perceptions about Inclusion of Stu- \\
dents with Disabilities in Physical Education \\
Classes \\
Abstract: The purpose of this study was to verify regu- \\
lar schooling teacher's attitudes toward inclusion children \\
with disabilities in the classes. For that, 90 physical edu- \\
cation teachers, from private and public schools, answe- \\
red to a scale with 18 affirmations. It was observed by \\
results that general tendency of teachers was negative \\
toward inclusion. This pessimism wasn't related to \\
teachers sex and time experience. Stronger teachers \\
pessimism was about their lack of preparing to work \\
with handicapped students. Teachers with less expe- \\
rience time showed more optimism about the benefits \\
of all students in inclusion settings. \\
Keywords: Social inequity. Special education. Disabled \\
children. Prejudice.
\end{tabular}

Movimento, Porto Alegre, v. 15, n. 02, p. 119-140, abril/junho de 2009. 
Percepciones de Profesores delante de la Inclusión de Alumnos con Deficiencia en Lecciones de Educación Física

RESUMEN: El objetivo de este estudio fue analizar las percepciones de profesores de educación física del sistema regular de enseñanza delante de la inclusión de alumnos con deficiencia. Para tanto, 90 profesores de educación física escolar respondieron a una escala con 18 afirmaciones. Se puede observar que la percepción general de los profesores fue negativa para con la inclusión. El pesimismo más fuerte de los profesores fue por no sentirse preparados para lidar con alumnos con deficiencias. Los profesores con pequeño tiempo de experiencia mostraron visiones más positivas en el que se refiere a los beneficios de los alumnos con la inclusión.

Palabras-Clave: Inequidad social. Educación especial. Ninõs con discapacidad. Prejuicio.

\section{REFERÊNCIAS}

AGUIAR, J.S.; DUARTE, E. Educação inclusiva: um estudo na área de educação física. Revista Brasileira de Educação Especial, Marília, v.11, n.2, p.223-240, 2005.

AMMAH, J.O.A.; HODGE, S.R. Secondary Physical Education Teachers' Beliefs and Practices in Teaching Students with Severe Disabilities: A Descriptive Analysis. High School Journal, Baltimore, v.89, n.2, p.40-54, 2006.

BAUMEL, R.C.R.C.; CASTRO, A.M. Materiais e recursos de ensino para deficientes visuais. In.: RIBEIRO, M.L.S.; BAUMEL, R.C.R.C. Educação especial: do querer ao fazer. São Paulo: Avercamp, 2003.

BRASIL. Constituição da República Federativa do Brasil. Brasília: Imprensa Oficial, 1988. 1996.

LDB. Lei de diretrizes e bases da educação. Brasília: Imprensa Oficial,

. PNE. Plano Nacional de Educação. Brasília: SEF/SEESP, 2001.

CRUZ, G.C.; FERREIRA, J.R. Processo de formação continuada de professores de educação física em contexto educacional inclusivo. Revista Brasileira de Educação Física e Esporte, São Paulo, v.19, n.2, p.163-180, 2005.

FARIAS, G.C. O programa de intervenção precoce como fator de inclusão da criança cega. Temas sobre Desenvolvimento, São Paulo, v.12, n.67, p.44-49, 2003.

Movimento, Porto Alegre, v. 15, n. 02, p. 119-140, abril/junho de 2009. 
GOLDER, G; NORWICH, B.; BAYLISS, P. Preparing Teachers to Teach Pupils with Special Educational Needs in More Inclusive Schools: Evaluating a PGCE Development. British Journal of Special Education, Cambridge, v.32, n.2, p.92-99, 2005

GORGATTI, M.G.; PENTEADO, S.H.N.W.; PINGE, M.D.; DE ROSE JÚNIOR., D. Atitudes dos professores de educação física do ensino regular com relação a alunos portadores de deficiência. Revista Brasileira de Ciência e Movimento, Brasília, v.12, n.2, p.63-68, 2004.

HUTZLER, Y. Attitudes toward the participation of individuals with disabilities in physical activity: a review. Quest, New York, v.55, p.347-373, 2003.

KOZUB, F.M.; PORRETTA, D.L. Interscholastic coache's attitudes toward integration of adolescents with disabilities. Adapted Physical Activity Quarterly, Champaign, v.15, p.328-344, 1998.

LAMASTER, K.; GALL, K.; KINCHIN, G.; SIEDENTOP, D. Inclusion practices of effective elementary specialists. Adapted Physical Activity Quarterly, Champaign, v.15, p.64-81, 1998.

LIMA, S.M.T.; DUARTE, E. Educação Física e a escola inclusiva. In.: SOBAMA. Temas em educação física adaptada. Curitiba: UFPR, 2001.

MELOGRANO, V.J.; LOOVIS, E.M. Status of physical education for handicapped students: a comparative analysis of teachers in 1980 and 1988. Adapted Physical Activity Quarterly, Champaign, v.8, p.28-42, 1991.

PALLA, A.C.; CASTRO, E.M. Atitudes de professores e estudantes de educação física em relação ao ensino de alunos com deficiência em ambientes inclusivos. Revista da Sobama, São Paulo, v.9, n.1, p.25-34, 2004.

PEDRINELLI, V.J. Possibilidades na diferença: o processo de "inclusão" de todos nós. Integração, Brasília, v.4, p. 31-34, 2002. Edição Especial.

PEDRINELLI, V.J.; VERENGUER, R.C.G. Educação física adaptada: introdução ao universo das possibilidades. In.: GORGATTI, M.G.; COSTA, R.F. Atividade física adaptada: qualidade de vida para pessoas com necessidades especiais. São Paulo: Manole, 2005.

RIZZO, T.L. Attributes related to teacher's attitudes. Perceptual and Motor Skills. Missoula, v.60, p.739-742, 1985.

RODRIGUES, D. AEducação física perante a educação inclusiva: reflexões conceptuais e metodológicas. Revista da Educação Física da UEM, Maringá, v.14, n.1, p.67-73, 2003.

SIDERIDIS, G.D.; CHANDLER, J.P. Assessment of Teacher Attitudes Toward Inclusion of Students with Disabilities: a Confirmatory Factor Analysis. Adapted Physical Activity Quarterly, Champaign, v.14, p.51-64, 1997.

Movimento, Porto Alegre, v. 15, n. 02, p. 119-140, abril/junho de 2009. 
SKARBREVIK, K.J. The Quality of Special Education for Students with Special Needs in Ordinary Classes. European Journal of Special Needs Education, London, v.20, n.4, p.387-401, 2005.

Recebido em: 18.01.2008

Aprovado em:16.02.2009

\section{ANEXO 1 - EsCALA APLICADA PARA OS PROFESSORES DE EDUCAÇÃo FÍSICA}

Prezado (a) professor (a):

O presente questionário visa avaliar quais as expectativas ou as experiências do professor de educação física em relação à presença de alunos com deficiência em suas aulas regulares. Você não precisa se identificar e deve assinalar apenas uma alternativa em cada afirmação, correspondendo àquela que melhor expressa seu grau de concordância. Desde já, agradeço sua colaboração.

A escala utilizada será a seguinte:

0 - não se aplica

1 - discordo totalmente da afirmação

2 - discordo quase totalmente da afirmação

3 - concordo quase totalmente com a afirmação

4 - concordo totalmente com a afirmação

Favor preencher os seguintes campos:

I - DADOS PESSOAIS
a) Idade:
b) Sexo: ( ) Feminino
( ) Masculino

Movimento, Porto Alegre, v. 15, n. 02, p. 119-140, abril/junho de 2009. 


\section{II - DADOS PROFISSIONAIS}
a) Tipo de escola: ( ) pública
( ) particular

b) Tempo de experiência em educação física escolar:

( ) menos de dois anos ( ) de 2 a 10 anos mais de 10 anos

\section{III - TRABALHO COM ALUNOS COM DEFICIÊNCIA}

a) Outras experiências com alunos com deficiência:

$$
\text { ( ) } \operatorname{sim} \quad(\text { ) não }
$$

b) Qual o tipo de deficiência apresentada pelos seus alunos?

( ) visual ( ) auditiva ( ) mental ( ) motora

( ) múltipla (descreva)

c) Já participou de cursos na área de educação física adaptada para pessoas com deficiência?
( ) $\operatorname{sim}$
( ) não

1- Eu sinto que tenho o conhecimento suficiente para atingir as necessidades educacionais de alunos com deficiência.
$\square 0$
$\square 1$
$\square 2$
$\square 3 \quad \square 4$

2- Com os conhecimentos que possuo, eu me sinto preparado para trabalhar com alunos com deficiência.
$\square 0$
$\square 1$
$\square 2$
$\square 3$
$\square 4$

3- Eu sinto que sou ou serei capaz de resolver ou controlar os problemas de comportamento dos alunos com deficiência.
$\square 0$
$\square 1$
$\square 2$
$\square 3 \quad \square 4$

4- Eu sinto que sou ou serei capaz de remediar os déficits de aprendizagem do aluno com deficiência.
$\square 0$
$\square 1$
$\square 2$
$\square 3 \quad \square 4$

Movimento, Porto Alegre, v. 15, n. 02, p. 119-140, abril/junho de 2009. 
5- Eu gosto ou gostaria de ter alunos com deficiência em minha aula.
$\square 0$
$\square 1$
$\square 2$
$\square 3$
$\square 4$

6- Eu pretendo participar de cursos e palestras para aumentar meus conhecimentos sobre os métodos de ensino para alunos com deficiência.

$\square 1$

$\square 2$

$\square 3$

$\square 4$

7- Eu avalio ou avaliarei os meus alunos com deficiência com os mesmos procedimentos utilizados para os alunos sem deficiência.
$\square 0$
$\square 1$
$\square 2$
$\square 3$
$\square 4$

8- Eu sinto que sou ou serei capaz de cumprir o programa de ensino proposto mesmo com a presença de alunos com deficiência.
$\square 0$
$\square 1$
$\square 2$
$\square 3$
$\square 4$

9- Eu sinto que consigo ou conseguirei motivar o aluno com deficiência da mesma forma que aquele sem deficiência.

$\square 0$

$\square 1$

$\square 2$

$\square 3$

$\square 4$

10- Eu sinto que a forma de tratamento do aluno com deficiência em minha aula é diferenciada.
$\square 0$
$\square 1$
$\square 2$
$\square 3$
$\square 4$

11- Eu sinto que os alunos com deficiência vão se beneficiar da interação oferecida por um programa em uma classe regular.
$\square 0$
$\square 1$
$\square 2$
$\square 3$
4

12- Eu sinto que os alunos sem deficiência irão se beneficiar com a inclusão de colegas com deficiência nas aulas regulares.
$\square 0$
$\square 1$
$\square 2$
$\square 3$
$\square 4$

13- Eu sinto que os alunos com deficiência são aceitos socialmente por seus colegas sem deficiência.

$\square 2$

$\square 3$

$\square 4$

Movimento, Porto Alegre, v. 15, n. 02, p. 119-140, abril/junho de 2009. 
14- Eu sinto que os alunos com deficiência são humilhados por seus colegas sem deficiência na aula regular.
$\square 0$
$\square 1$
$\square 2$
$\square 3$
$\square 4$

15- Eu sinto que existem materiais instrucionais suficientes para que eu ensine os alunos com deficiência.
$\square 0$
$\square 1$
$\square 2$
$\square 3$
$\square 4$

16- Eu sinto que são oferecidos pela escola todos os serviços de suporte suficientes para que eu ensine alunos com deficiência (médico, psicólogo, fonoaudiólogo, auxiliares).
$\square 0$
$\square 1$
$\square 2$
$\square 3$
$\square 4$

17- Eu sinto que eu tenho recursos suficientes da escola para adquirir os materiais necessários para planejar as aulas e trabalhar com os alunos com deficiência.
$\square 0$
$\square 1$
$\square 2$
$\square 3$
$\square 4$

18- As instalações da escola em que trabalho são adaptadas para receber um aluno com deficiência.
$\square 0$
$\square 1$
$\square 2$
$\square 3$
$\square 4$

Movimento, Porto Alegre, v. 15, n. 02, p. 119-140, abril/junho de 2009. 